\title{
Elective caesarean section and neonatal outcome: an observational study from a tertiary hospital in Mysore, Karnataka, India
}

\author{
Mamatha Shivanagappa ${ }^{1}$, Vinutha K. Veerabhadrappa ${ }^{1 *}$, \\ Deepthi Thandaveshwar ${ }^{2}$, Madhumitha Mahesh ${ }^{1}$
}

\begin{abstract}
${ }^{1}$ Department of Obstetrics and Gynecology, ${ }^{2}$ Department of Pediatrics, JSS Medical College, JSS Academy of Higher Education and Research (Deemed to be University), Mysore, Karnataka, India
\end{abstract}

Received: 09 November 2018

Accepted: 12 December 2018

*Correspondence:

Dr. Vinutha K. Veerabhadrappa,

E-mail: drvinuthakv92@gmail.com

Copyright: () the author(s), publisher and licensee Medip Academy. This is an open-access article distributed under the terms of the Creative Commons Attribution Non-Commercial License, which permits unrestricted non-commercial use, distribution, and reproduction in any medium, provided the original work is properly cited.

\begin{abstract}
Background: Globally 18.6 percent of all births occur by Caesarean Section (CS) and the trend is increasing. In India CS rates have risen from $2.9 \%$ in 1992 to $17.2 \%$ in 2015 . The optimal timing of CS is still being investigated. Data with regard to elective CS and neonatal outcome from India is sparse and this study aimed to obtain the same in the setting of a South Indian Hospital. The objective was to evaluate neonatal outcome and NICU admissions in elective CS

Methods: This was a retrospective study conducted at a tertiary care referral hospital and data collected was of deliveries conducted from Jan 2017 to July 2018. All term singleton pregnancies (>37 gestational weeks) scheduled for elective CS were included in the study.

Results: A total of 3174 Caesarean Sections were performed during the study period of which 1087 were elective CS and 2087 were done on an emergent basis. Of these elective CS, $425(39 \%)$ were performed at early term (37+0 until $38+6)$ and $662(61 \%)$ were performed at full term (>39 weeks). Analysis of adverse neonatal outcomes revealed that a significantly higher rate of NICU admission, low birth weight, respiratory complications in newborns delivered at early term than in those delivered at full term.

Conclusions: In the present study newborns delivered at $37-38$ weeks of gestation had a higher rate of NICU admission, low birth weight and respiratory complications compared to newborns delivered after 39 weeks of gestation. Neonatal outcome was found to be better in those elective CS done after 39 weeks in comparison to those delivered at early term $(<39$ weeks $)$.
\end{abstract}

Keywords: Caesarean Section, Elective LSCS, Neonatal outcomes

\section{INTRODUCTION}

The rates of caesarean deliveries have been steadily rising worldwide in the last few decades. At present 18.6 percent of all births occur by Caesarean Section (CS) globally and the trend is increasing. ${ }^{1}$

In the India the Caesarean section rates have risen from around $2.9 \%$ in the year 1992 to $17.2 \%$ in $2015 .^{2}$ In 2006 , the United States cesarean delivery rate of $31.1 \%$ was at an all-time high, making cesarean delivery the most common surgical procedure performed in American women. ${ }^{3,4}$ According to WHO proportion of CS to the total births is considered as one of the important indicators of emergency obstetric care and a figure of 5$15 \%$ is considered an acceptable rate of Caesarean section at population level., ${ }^{5,6}$ Several studies have brought out a clear need for further investigation into the costs of elective cesarean delivery. ${ }^{7,8}$ The number of 
elective caesarean sections are seeing an increasing trend. The exact rates for elective and emergency caesarean section in India are not readily available. As per 2009 study conducted in Ireland around $11.7 \%$ of all births were delivered by elective CS. ${ }^{9}$

With regard to timing of elective Caesarean Section the consensus is still evolving.

The NICE guidelines and RCOG guidelines recommend that elective Caesarean section should not routinely be carried out before 39 weeks of gestation. ${ }^{10,11}$

Studies have found decreasing risk for the newborn for mortality and NICU admission in full term caesarean section compared to early term caesarean section. ${ }^{12}$ Many studies are still underway to address the question whether there is an increased risk of mortality for mothers with a full term (39 weeks) elective caesarean section compared to early term caesarean section. ${ }^{13}$

Controversy remains on whether a trial of labor or an elective repeat cesarean delivery is preferable for a woman with a history of cesarean delivery.

Historically, concerns regarding the increased risk of uterine rupture and perinatal asphyxia in trial of labor after cesarean compared with planned repeat cesarean have swayed obstetricians away from recommending a trial of labor after cesarean delivery; however, the absolute risk of perinatal asphyxia remains small. ${ }^{14,15}$

A paucity of data exists regarding the cost of elective repeat cesarean delivery as compared with other delivery options. Prior studies have lacked large enough patient numbers to confidently estimate the costs of the rare complications from each type of delivery, therefore demonstrating a clear need for further investigation into the costs of elective cesarean delivery.

The study was conducted to determine the rate and type of neonatal complications of newborn delivered by elective CS at early term (37-38 weeks) versus full term (>39 weeks).

\section{METHODS}

This was a retrospective study conducted at a tertiary care referral hospital in South India and data collected was of deliveries conducted from January 2017 to July 2018.

\section{Inclusion criteria}

- All term singleton pregnancies (>37 gestational weeks) scheduled for elective CS.

\section{Exclusion criteria}

- Gestational age below completed 37 weeks,

- Multiple pregnancy,
- Pregnancy induced hypertension,

- Gestational diabetes,

- Placenta previa,

- Low-lying placenta,

- Placental abruption,

- Prolonged labor,

- Non-reassuring fetal status,

- IUGR,

- Meconium defecation and any other cause of emergency CS.

Gestation age was determined by first trimester USG. The maternal factors that were examined were age, parity, indication for elective CS.

The neonatal factors that were examined were weight, presence of ARDS, admission to NICU. NICU admission criteria was be followed.

Labor was defined as subjectively painful contractions more frequent than every 10 minutes, with the obstetrician's documentation of cervical change or the words "active labor" in the chart.

The primary outcome was admission to the NICU, defined as any length of time spent in the NICU after delivery, and included neonates who transitioned for a period of time due to a clinical assessment of respiratory distress.

Maternal medical characteristics included body mass index (BMI) calculated using pre-pregnancy weight and height, history of a successful VBAC, chronic medical disease (autoimmune disease, chronic hypertension, or pre-existing diabetes), and diabetes during pregnancy (both pre-existing and gestational diabetes).

Pregnancy characteristics included evidence of macrosomia (neonate more than $90 \%$ weight for gestational age), attempt at amniocentesis for fetal lung maturity, induction of labor, non-reassuring fetal heart tones, and finally, chorioamnionitis (documented by the obstetrician and defined as maternal fever plus one of the following: fundal tenderness, purulent discharge, and maternal tachycardia).

Characteristics regarding the neonate included gestational age (based on last menstrual period or ultrasonography), sex, and birth weight.

Neonatal outcomes included any oxygen use during delivery room resuscitation, highest level of delivery room resuscitation required (routine resuscitation only, blow-by oxygen, mask continuous positive airway pressure, bag or mask ventilation, or endotracheal intubation), neonate disposition (well-baby nursery compared with NICU), endotracheal intubation outside the delivery room, hypoglycemia requiring NICU stay, respiratory distress requiring NICU stay (need for oxygen 
or other ventilatory support), and type of ventilatory support needed in NICU (conventional mechanical ventilation, oxygen hood, nasal cannula, or continuous positive airway pressure)

\section{Statistical analysis}

Categorical and continuous variables are expressed as number (percentage) and mean \pm standard deviation respectively.

Chi square was applied to compare categorical variables and student's $t$ test was used to compare parametric continuous variables.

\section{RESULTS}

A total of 3174 Caesarean Sections were performed during the study period of which 1087 were elective CS and 2087 were done on an emergent basis. Of these elective CS, 425 (39\%) were performed at early term $(37+0$ until $38+6)$ and $662(61 \%)$ were performed at full term (>39 weeks). The causes for elective Caesarean delivery were previous caesarean section in $60 \%$ (652), placenta praevia in $14 \%$ (152), breech presentation in $13 \%$ (141), suspected cephalopelvic disproportion in $3 \%$ (33), maternal requested CS in $4 \%$ (43) and other causes in $6 \%$ as shown in Table 1.

Table 1: Comparison of baseline clinical characteristics and neonatal outcome in the two groups.

\begin{tabular}{|c|c|c|c|}
\hline Characteristic & $\begin{array}{l}\text { Elective caesarean delivery 37-38 } \\
\text { weeks }(n=425)\end{array}$ & $\begin{array}{l}\text { Elective caesarean delivery }>39 \\
\text { weeks }(n=662 \text { ) }\end{array}$ & $p$ value \\
\hline Maternal Age & $26.34 \pm 5.1$ & $26.9 \pm 4.9$ & 0.275 \\
\hline \multicolumn{3}{|l|}{ Cause of Caesarean } & \multirow{5}{*}{0.254} \\
\hline Previous LSCS & 290 & 362 & \\
\hline Breech & 56 & 85 & \\
\hline Placental Praevia & 72 & 80 & \\
\hline Maternal Request & 14 & 29 & \\
\hline Birth Weight of newborn & $2.6 \pm 0.36$ & $2.9 \pm 0.41$ & 0.273 \\
\hline APGAR min 1 & 9 & 9 & 0.5 \\
\hline APGAR min 5 & 9 & 8 & 0.43 \\
\hline NICU admission & $29(6 \%)$ & $12(1.8 \%)$ & $<0.001$ \\
\hline Respiratory Distress & 24 & 11 & 0.005 \\
\hline $\mathrm{O} 2$ supplementation & 15 & 5 & 0.006 \\
\hline Assisted ventilation & 8 & 3 & 0.0288 \\
\hline Length of hospital stay & $7.6 \pm 1.7$ & $5.8 \pm 1.9$ & 0.026 \\
\hline
\end{tabular}

There was no significant difference between the mean age of mothers in the two groups.

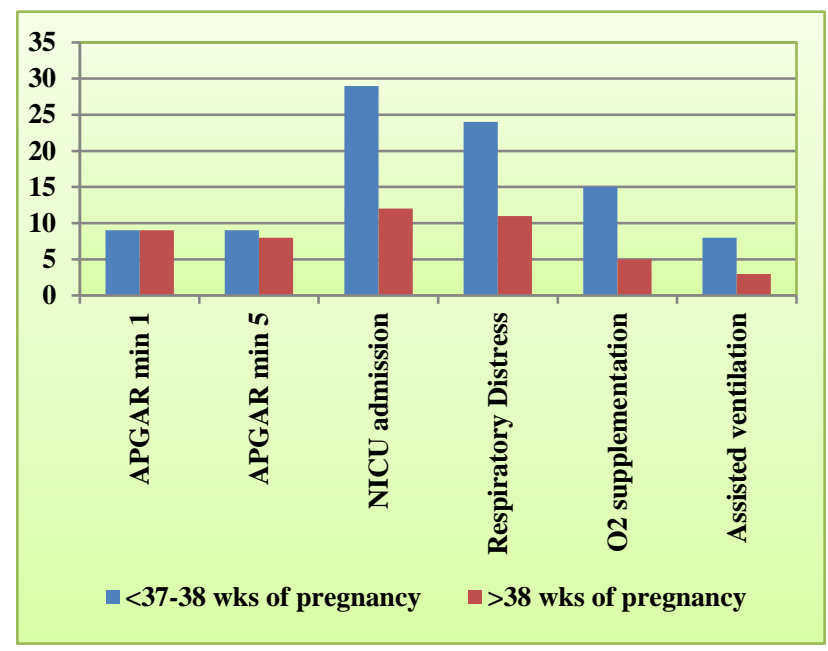

Figure 1: Neonatal outcomes and timing of LSCS
As shown in Table 1 previous caesarean was more common in mothers who delivered between 37-38 weeks when compared to mothers who delivered after 39 weeks. No significant differences existed in the male to female ratio between the groups. Analysis of adverse neonatal outcomes revealed that a significantly higher rate of NICU admission, low birth weight, respiratory complications in newborns delivered at early term than in those delivered at full term as shown in Figure 1. There was no significant difference between the groups in regard to 5-min Apgar score.

\section{DISCUSSION}

Traditionally CS were done after 37 weeks assuming foetal lung maturation by the end of 37 weeks. ACOG guidelines recommend that repeat elective Caesarean sections should be performed at or after 39 weeks of gestation to prevent neonatal respiratory complications. ${ }^{16}$ Still the number of elective Caesarean Section done before 39 weeks is significant. In a study done at UK 
around $60 \%$ of elective caesarean sections are performed beyond 39 weeks of gestation. ${ }^{9}$

Studies have shown favourable neonatal outcome with respect to late term $\mathrm{CS}$ in terms of lower incidence of respiratory disorders and NICU admissions. ${ }^{17}$ The optimal time point for performing elective caesarean section is debated and still being explored in many studies. ${ }^{18}$ Historically, concerns regarding the increased risk of uterine rupture and perinatal asphyxia in trial of labor after cesarean compared with planned repeat cesarean have swayed obstetricians away from recommending a trial of labor after cesarean delivery; however, the absolute risk of perinatal asphyxia remains small. $^{14,15}$

In the present study newborns delivered at 37- 38 weeks of gestation had a higher rate of NICU admission, low birth weight and respiratory complications compared to newborns delivered after 39 weeks of gestation. Caesarean sections late in pregnancy (39 weeks of gestation) may lead to an increased rate of emergency Caesarean sections due to PROM or labor onset, thereby increasing the risks for both the mother and newborn Given the increasing rates of primary cesarean delivery and the concomitant decrease in VBACs, once a woman has had a primary cesarean delivery, we must consider the risks that this place on her subsequent deliveries and subsequent neonates. Indeed, this argues for greater selectivity in performing a cesarean delivery in the first place, and certainly a greater need for counselling before a primary elective cesarean delivery.

\section{Strengths and weaknesses of this study}

The study included 1087 elective caesarean deliveries which is relatively a large sample. The data with regard to Indian settings is lacking with regard to timing of elective caesarean and neonatal outcome. There are some studies which have been attempted though with lesser sample size. This was an observational study. The study does not take in to account the deliveries originally scheduled for elective caesarean section but had emergency caesarean sections. In the present study neonatal outcome was considered only till 14 days postdelivery.

\section{CONCLUSION}

There is no clear consensus on accurate timing of elective LSCS. However, the caesarean rate in all tertiary care centres are high. The present study showed a better neonatal outcome for patients undergoing elective LSCS after 39 weeks.

\section{ACKNOWLEDGMENTS}

Authors would like to thank Heads of Neonatology Pediatrics and OBG Dept of JSS Hospital, Dr. Yatish
Assistant Professor department of animal genetics and bio statistics for their assistance during the study.

Funding: No funding sources

Conflict of interest: None declared

Ethical approval: The study was approved by the Institutional Ethics Committee

\section{REFERENCES}

1. Betrán AP, Ye J, Moller AB, Zhang J, Gülmezoglu AM, Torloni MR. The increasing trend in caesarean section rates: Global, regional and national estimates: 1990-2014. PLoS ONE 2016;11(2):e0148343.

2. International Institute for Population Sciences, Mumbai (2017)National Family Health Survey (NFHS-4) 2015-16 India Fact sheet

3. Hamilton BE, Martin JA, Ventura SJ. Births: preliminary data for 2006. National Vital Stat Rep. 2007;56(7):1-8.

4. MacDorman MF, Menacker F, Declercq E. Cesarean birth in the United States: epidemiology, trends, and outcomes. Clin Perinatol. 2008;35(2):293-307.

5. WHO. Appropriate technology for birth. Lancet. 1985;326(8452):436-7.

6. WHO. 1994. Indicators to Monitor Maternal Health Goals. Report of a Technical Working Group, Geneva, 8-12 Nov, 1993.

7. National Institutes of Health. NIH Consensus Development Program. NIH State-of-the-Science Conference: cesarean delivery on maternal request. 2006 Mar 27-29; Available Online :http://consensus.nih.gov/2006/2006CesareanSOS02 7main.htm.

8. Zupancic JA. The economics of elective cesarean section. Clin Perinatol. 2008;35(3):591-9.

9. Sinnott S-J, Brick A, Layte R, Cunningham N, Turner MJ. National Variation in Caesarean Section Rates: A Cross Sectional Study in Ireland. PLoS One.2016;11(6):e0156172.

10. National Institute for Health and Care Excellence (NICE). CG132 Caesarean section. Available at https://www.nice.org.uk/guidance/cg132.

11. Royal College of Obstetricians and Gynecologists (RCOG). Birth after Previous Caesarean Birth 2015. Available at https://www.rcog.org.uk/en/guidelinesresearch-services/guidelines/gtg45/.

12. Salim R, Shalev E. Health implications resulting from the timing of elective cesarean delivery. Reprod Biol Endocrinol: RB\&E. 2010;8(1):68.

13. Prediger B, Polus S, Mathes T, Bühn S, Louwen F,2 Neugebauer EAM et al. Systematic Reviews (2018) 7:119.

14. Spong CY, Landon MB, Gilbert S, Rouse DJ, Leveno KJ, Varner MW, et al. Risk of uterine rupture and adverse perinatal outcome at term after cesarean delivery. Obstet Gynecol. 2007;110(4):8017.

15. Smith GC, Pell JP, Cameron AD, Dobbie R. Risk of perinatal death associated with labor after previous 
cesarean delivery in uncomplicated term pregnancies. JAMA. 2002;287(20):2684-90.

16. American College of Obstetricians and Gynecologists. ACOG practice bulletin no. 97: fetal lung maturity. Obstet Gynecol. 2008;112(3):717-26.

17. Salim R, Shalev E. Health implications resulting from the timing of elective cesarean delivery. Reprod Biol Endocrinol: RB\&E. 2010;8(1):68.

18. Glavind J, Kindberg SF, Uldbjerg N, Henriksen TB. Timing of elective cesarean section and neonatal morbidity: a randomized controlled trial. Int $\mathrm{J}$ Gynaecol Obstet. 2012;119:S358.

Cite this article as: Shivanagappa M,

Veerabhadrappa VK, Thandaveshwar D, Mahesh M.

Elective caesarean section and neonatal outcome: an observational study from a tertiary hospital in Mysore, Karnataka, India. Int J Reprod Contracept Obstet Gynecol 2019;8:14-8. 